\title{
ANALISIS PERAN SUBSEKTOR PERTANIAN TERHADAP PEMBANGUNAN KABUPATEN KARANGANYAR; SEBUAH PENDEKATAN COMPARATIVE PERFORMANCE INDEX
}

\author{
Fransisca Erna S. ${ }^{1)}$, Mohamad Harisudin ${ }^{2)}$, Wiwit Rahayu ${ }^{3)}$ \\ 1. Mahasiswa Program Studi Agribisnis Fakultas Pertanian UNS \\ 2. Dosen Pembimbing Utama \\ 3. Dosen Pembimbing Pendamping \\ Program Studi Agribisnis, Fakultas Pertanian Universitas Sebelas Maret Surakarta \\ Jl. Ir. Sutami No.36 A Kentingan Surakarta 57126 Telp./Fax (0271) 637457 \\ Email: fransiscaernas@gmail.com
}

\begin{abstract}
The objective of this study was to determine how much of the total share, rate of contribution and rate of growth of agriculture sector on regional development in Karanganyar; determine the classification of agriculture sector in Karanganyar using Klassen typology; and knowing the agriculture sector featured in Karanganyar regency. The research location was Karanganyar Regency. The data used in this study is primary data and secondary data. Data analysis methods used were: (1)Analysis of the magnitude of the total share of agricultural subsectors using shift share analysis; (2)Identification of the contribution and the growth rate of agriculture subsector; (3)The classification of agriculture subsector in Karanganyar using Klassen typology; and (4)Identification of featured subsector agricultural sector in Karanganyar using Comparative Performance Index (CPI). The results showed: total share of food crops, plantation subsector, livestock susbector, forestry subsector, and the fisheries subsector respectively 173.644,66 million rupiah; 24.928,24 million rupiah; 56.674,21 million rupiah; 829,48 million rupiah; and 1.153,37 million rupiah. Contribution of the food-stuff crops subsector, plantation subsector, animal husbandry subsector, forestry subsector, and fisheries subsector respectively by $66.94 \% ; 8.71 \% ; 23.36 \%$; $0.48 \%$; and $0.52 \%$. The growth rate of the food-stuff crops subsector, plantation subsector, animal husbandry subsector, forestry subsector, and fisheries subsector respectively by 6.29\%; 6.70\%; 5.41\%; 3.92\%; and 5.16\%. Karanganyar animal husbandry subsector is developed and emerging subsector. Food-stuff crops subsector, plantation subsector, forestry subsector, and fisheries subsector were classified in growing subsectors but depressed. The first featured the agricultural subsector based on analysis of the CPI was the food crops subsector.
\end{abstract}

Keyword: comparative performance index, klassen typology, shift share analysis, the role of agriculture subsectors

Abstrak: Penelitian ini bertujuan untuk (1) mengetahui besar total share, kontribusi, dan laju pertumbuhan subsektor pertanian terhadap pembangunan Kabupaten Karanganyar, (2) mengklasifikasikan subsektor pertanian di Kabupaten Karanganyar menggunakan tipologi klassen, dan (3) mengetahui subsektor pertanian unggulan Kabupaten Karanganyar. Lokasi penelitian dipilih secara sengaja (purposive) yaitu Kabupaten Karanganyar. Data yang digunakan adalah data primer dan data sekunder. Analisis data yang digunakan adalah analisis shift share, analisis kontribusi dan laju pertumbuhan, analisis tipologi klassen, dan analisis comparative performance index. Hasil penelitian menunjukkan total share subsektor tanaman bahan makanan, subsektor perkebunan, subsektor peternakan, subsektor kehutanan, dan subsektor perikanan Kabupaten Karanganyar masing-masing sebesar 173.644,66 juta rupiah; 
24.928,24 juta rupiah; 56.674,21 juta rupiah; 829,48 juta rupiah; dan 1.153,37 juta rupiah. Kontribusi subsektor tanaman bahan makanan, subsektor perkebunan, subsektor peternakan, subsektor kehutanan, dan subsektor perikanan masing-masing sebesar $66,94 \% ; 8,71 \% ; 23,36 \% ; 0,48 \%$; dan $0,52 \%$. Laju pertumbuhan subsektor tanaman bahan makanan, subsektor perkebunan, subsektor peternakan, subsektor kehutanan, dan subsektor perikanan masing-masing sebesar 4,88\%; 5,75\%; 5,27\%; 4,01\%; dan 5,89\%. Subsektor peternakan Kabupaten Karanganyar merupakan subsektor maju dan berkembang. Subsektor tanaman bahan makanan, subsektor perkebunan, subsektor kehutanan, dan subsektor perikanan diklasifikasikan dalam subsektor berkembang tapi tertekan. Subsektor pertanian unggulan pertama berdasarkan analisis CPI adalah subsektor tanaman bahan makanan.

Kata kunci : comparative performance index, peran subsektor pertanian, shift share, tipologi klassen

\section{PENDAHULUAN}

Otonomi daerah adalah pemberian otoritas bagi pemerintahan lokal untuk mengatur rumah tangga (daerah) sendiri. Tujuan utama dari otonomi daerah adalah peningkatan kesejahteraan masyarakat lokal. Kesejahteraan masyarakat dapat dicapai melalui strategi pembangunan yang tepat. Otonomi Daerah ditandai dengan diterbitkannya UndangUndang Nomor 22 Tahun 1999 tentang Pemerintahan Daerah, daerah berhak mengatur rumah tangganya sendiri. Saat ini, segala hal yang berkaitan dengan otonomi daerah, diatur dalam Undang-Undang Nomor 23 Tahun 2014 tentang Pemerintahan Daerah dan telah mengalami perubahan kedua yang diatur dalam Undang-Undang Nomor 9 Tahun 2015. Sumber daya pembangunan seperti alam, manusia, modal, dan teknologi mulai bergeser ke daerah. Dalam mengatur rumah tangga daerah, hendaknya pemerintah daerah menerapkan prinsip otonomi yang bertanggung jawab yaitu prinsip untuk mengurus dan mengatur rumah tangga sendiri berdasarkan aspirasi masyarakat dan potensi daerah. Berdasarkan aspirasi masyarakat berarti menuntut perencanaan pembangunan partisipatif. Sementara berdasarkan potensi daerah, berarti menuntut perencanaan pembangunan menganut prinsip prioritas (Saragih, 2015).

Kabupaten Karanganyar merupakan salah satu daerah otonom di Provinsi Jawa Tengah yang memberikan sumbangan kontribusi PDRB Jawa Tengah. Perekonomian Kabupaten Karanganyar ditopang oleh 9 sektor. Sembilan sektor yang menopang perekonomian Kabupaten Karanganyar yaitu sektor industri pengolahan, sektor pertanian, sektor perdagangan, sektor jasa-jasa, sektor angkutan dan komunikasi, sektor bangunan, sektor lembaga keuangan, sewa bangunan, dan jasa perusahaan, sektor listrik, gas, dan, air minum, dan sektor pertambangan dan penggalian. Peranan sektor pertanian dalam pembangunan ekonomi sangat penting karena sebagian anggota masyarakat di negara-negara sedang berkembang menggantungkan hidupnya pada sektor tersebut. Jika para perencana dengan sungguh - sungguh memperhatikan kesejahteraan masyarakatnya, maka satusatunya cara adalah dengan meningkatkan kesejahteraan sebagian besar anggota masyarakatnya yang hidup di sektor pertanian itu sendiri (Arsyad, 1992). Daerah-daerah di negara sedang berkembang pada umumnya merupakan daerah pertanian, karena itu cara pembangunan daerah yang terbaik dianut adalah dengan pengembangan sektor petanian dengan alasan (Arsyad, 2005): (1) Sebagian besar penduduk hidup dan bekerja di sektor pertanian, pada kenyataannya pertanian cenderung dikembangkan di daerah dengan pertumbuhan ekonomi rendah disertai dengan laju pertumbuhan penduduk yang cukup tinggi, (2) Jika kemiskinan di daerah pertanian terus dibiarkan, akan terjadi arus urbanisasi yang dapat menyebabkan terjadinya pengangguran yang cukup banyak di kota-kota besar dengan segala konsekuensinya (3) Jika dilakukan pembangunan sektor industri, perkembangan di sektor ini tidak dapat atau kurang mampu untuk menampung tambahan tenaga kerja yang senantiasa terjadi. (4) Sektor pertanian perlu dibangun agar menghasilkan tambahan pangan guna memenuhi kebutuhan masyarakat yang 
senantiasa bertambah serta untuk diekspor guna memperoleh devisa.

Pertumbuhan sektor pertanian suatu daerah pada dasarnya dipengaruhi oleh keunggulan kompetitif suatu daerah, spesialisasi wilayah serta potensi pertanian yang dimiliki oleh daerah tersebut. Adanya potensi pertanian di suatu daerah tidaklah mempunyai arti bagi pertumbuhan pertanian daerah tersebut bila tidak ada upaya memanfaatkan dan mengembangkan potensi pertanian secara optimal. Oleh karena itu pemanfaatan dan pengembangan seluruh potensi pertanian yang potensial harus menjadi prioritas utama untuk digali dan dikembangkan dalam melaksanakan pembangunan pertanian daerah secara utuh (Maria, 2007). Sektor pertanian sendiri terdiri dari lima subsektor yaitu tanaman bahan makanan, perkebunan, peternakan, kehutanan, dan perikanan. Kontribusi sektor pertanian Kabupaten Karanganyar tahun 2012-2014 berturut-turut sebesar 21,55 persen, 20 persen, dan 19,54 persen. Kontribusi sektor pertanian menurun tiap tahunnya sehingga Tantangan yang dihadapi Kabupaten Karanganyar dalam pelaksanaan strategi pembangunan adalah bagaimana mempertahankan dan meningkatkan produktivitas dan efisiensi sektor pertanian sehingga dapat memberikan nilai tambah yang sebesar-besarnya bagi masyarakat dengan mengoptimalkan segala potensi yang dimiliki daerah.

Analisis Shift Share merupakan salah satu eknik yang relevan untuk menganalisis daerah berdasarkan regional dan pembagian masing-masing sektor. Dengan melakukan analisis shift share, memungkinkan untuk mengekplorasi keuntungan dari daerah setempat serta untuk mengidentifikasi pertumbuhan atau pertumbuhan industri yang layak untuk dikembangkan lebih lanjut (Dinc, 2002). Keuntungan utama dari analisis shift share adalah kesederhanaannya yang penggunaannya tidak membutuhkan pengumpulan data primer, dimana peneliti akan dimudahkan dalam pengumpulan data, menghemat dan biaya yang dikeluarkan. Penghitungan dalam analisis shift share juga relatif sederhana jika dibandingkan dengan alat analisis lain yang juga digunakan dengan tujuan untuk menentukan kinerja atau produktivitas kerja perekonomian daerah (Yun Shi dan Yang, 2008).

Tipologi Klassen merupakan salah satu alat analisis ekonomi regional, yaitu alat analisis yang digunakan untuk mengetahui gambaran tentang pola dan struktur pertumbuhan ekonomi suatu daerah (Sjafrizal, 2008). Pada pengertian ini, tipologi klassen dilakukan dengan membandingkan pertumbuhan ekonomi Kabupaten Karanganyar dengan pertumbuhan ekonomi Provinsi Jawa Tengah dan membandingkan kontribusi Kabupaten Karanganyar dengan kontribusi Provinsi Jawa Tengah. Kemudian dibagi menjadi 4 klasifikasi yaitu: sektor maju dan berkembang, sektor berkembang tapi tertekan, sektor potensial, dan sektor tertinggal.

Penelitian ini bertujuan untuk (1) mengetahui besar total share, kontribusi, dan laju pertumbuhan subsektor pertanian terhadap pembangunan Kabupaten Karanganyar, (2) mengklasifikasikan subsektor pertanian di Kabupaten Karanganyar menggunakan tipologi klassen, dan (3) mengetahui subsektor pertanian unggulan Kabupaten Karanganyar.

\section{METODE PENELITIAN}

Metode dasar yang digunakan dalam penelitian ini adalah metode deskriptif analisis. Penelitian dilakukan di Kabupaten Karanganyar pada Juni 2016 hingga September 2016. Jenis data yang digunakan adalah data primer dan sekunder. Data primer bersumber dari wawancara dengan staff pemerintahan Kabupaten Karanganyar dan data sekunder bersumber dari BPS Karanganyar, BAPPEDA Karanganyar, dan BPS Jawa Tengah. Adapun data yang dianalisis meliputi data PDRB Kabupaten Karanaganyar dan Provinsi Jawa Tengah dari tahun 20092013 dengan menggunakan ADHK 2000. Adapun analisis data dilakukan dengan cara sebagai berikut:

$$
\begin{aligned}
& \text { Analisis Shift Share } \\
& \text { National Growth } \\
& \mathrm{NG}=\mathrm{Ei}^{\mathrm{t}}\left(\frac{\mathrm{N}^{\mathrm{t}+1}}{\mathrm{~N}^{\mathrm{t}}}-1\right) \\
& \text { Industry Mix } \\
& \mathrm{IM}=\mathrm{Ei}^{\mathrm{t}}\left(\frac{\mathrm{Ni}^{\mathrm{t}+1}}{\mathrm{Ni}^{\mathrm{t}}}-\frac{\mathrm{N}^{\mathrm{t}+1}}{\mathrm{~N}^{\mathrm{t}}}\right)
\end{aligned}
$$


Competitive Share

$\mathrm{CS}=\mathrm{Ei}^{\mathrm{t}}\left(\frac{\mathrm{Ei}^{\mathrm{t}+1}}{\mathrm{Ei}^{\mathrm{t}}}-\frac{\mathrm{Ni}^{\mathrm{t}+1}}{\mathrm{Ni}^{\mathrm{t}}}\right)$

Total Shift Share

$\mathrm{TSS}=\mathrm{NG}+\mathrm{IM}+\mathrm{CS}$

Keterangan $: \mathrm{Ei}^{\mathrm{t}}=$ PDRB subsektor pertanian pada tahun $t$ di Kabupaten Karanganyar; $\mathrm{Ei}^{\mathrm{t}+1}$ $=$ PDRB subsektor pertanian pada tahun $\mathrm{t}+1 \mathrm{di}$ Kabupaten Karanganyar; $\mathrm{N}^{\mathrm{t}+1}=$ Total PDRB pada tahun $\mathrm{t}+1$ di Provinsi Jawa Tengah; $\mathrm{N}^{\mathrm{t}}$ : Total PDRB pada tahun $\mathrm{t}$ di Provinsi Jawa Tengah; $\mathrm{Ni}^{\mathrm{t}+1}=$ PDRB subsektor analisis pada tahun $\mathrm{t}+1$ di Provinsi Jawa Tengah; $\mathrm{Ni}^{\mathrm{t}}=$ PDRB subsektor analisis pada tahun $t$ di Provinsi Jawa Tengah

\section{Kontribusi dan Laju Pertumbuhan}

Kontribusi $=\frac{\text { PDRB Subsektor Pertanian }}{\text { PDRB Total Sektor Pertanian }} \times 100 \%$

Laju Pertumbuhan=

$=\frac{\text { PDRB Subsektor } \mathrm{i}(\text { thn acuan }- \text { thn sebelumnya })}{\text { PDRB Subsektor i tahun sebelumnya }} \times 100 \%$

\section{Tipologi Klassen}

\begin{tabular}{|l|c|c|}
\hline $\begin{array}{r}\text { Rerata } \\
\text { Kontribusi } \\
\text { Sub } \\
\text { sektor }\end{array}$ & yi $>\mathrm{Yi}$ & yi $<\mathrm{Yi}$ \\
$\begin{array}{l}\text { Rerata } \\
\text { Laju } \\
\text { Pertumbuh } \\
\text { an subsektor }\end{array}$ & & \\
\hline ri $>$ Ri & $\begin{array}{c}\text { Tipe I } \\
\text { Subsektor } \\
\text { Maju dan } \\
\text { Berkembang }\end{array}$ & $\begin{array}{c}\text { Tipe II } \\
\text { Subsektor } \\
\text { Berkembang } \\
\text { tapi Tertekan }\end{array}$ \\
\hline ri $<$ Ri & $\begin{array}{c}\text { Tipe III } \\
\text { Subsektor } \\
\text { Potensial }\end{array}$ & $\begin{array}{c}\text { Tipe IV } \\
\text { Subsektor } \\
\text { Tertinggal }\end{array}$ \\
\hline
\end{tabular}

Keterangan: ri $=$ rerata laju pertumbuhan Kabupaten Karanganyar; $\mathrm{Ri}=$ rerata laju pertumbuhan Provinsi Jawa Tengah; yi = rerata kontribusi Kabupaten Karanganyar; $\mathrm{Yi}=$ rerata kontribusi Provinsi Jawa Tengah

Comparative Performance Index

$A_{i j}=X_{i j}(\min ) \times 100 / X_{i j}(\min )$

$A_{(i+1, j)}=\left(X_{(i+1, j)}\right) / X_{i j}(\min ) \times 100$

$I_{i j}=A_{i j} \times P_{j}$
$I_{i}=\sum_{j=1}^{n}\left(I_{i}\right)$

Keterangan : $A_{i j}=$ nilai alternatif ke-i pada kriteria ke-j; $X_{i j}(\min )=$ nilai alternatif ke-I pada kriteria awal minimum ke-j; $A_{(i+1, j)}=$ nilai alternatif ke-i +1 pada kriteria ke-j; $X_{(i+1, j)}=$ nilai alternatif ke-i +1 pada kriteria awal ke-j; $P_{j}=$ bobot kepentingan kriteria ke-j; $I_{i j} \quad=$ indeks alternatif ke-i; $I_{i}=$ indeks gabungan kriteria pada alternatif ke-i; $\mathrm{I}=1,2$, $3, \ldots, n ; j=1,2,3, \ldots ., m$

\section{HASIL DAN PEMBAHASAN}

\section{Gambaran Umum}

Kabupaten Karanganyar merupakan salah satu kabupaten di antara 35 kabupaten dan kota di Provinsi Jawa Tengah. Berdasarkan perhitungan garis bujur dan garis lintang, Kabupaten Karanganyar terletak antara $110^{\circ}$ $40 "-110^{0} 70 "$ Bujur Timur dan $7^{0} 28^{\prime}-7^{0} 46^{\prime}$ Lintang Selatan. Secara administratif, Kabupaten Karanganyar terdiri dari 17 Kecamatan, yang mencakup sebanyak 177 desa/kelurahan (15 Kelurahan dan 162 Desa). Desa/Kelurahan tersebut terdiri dari 1.091 dusun, 2.313 dukuh, 1.835 RW dan 6.020 RT. Klasifikasi desa/kelurahan pada tahun 2004 terdiri dari desa swadaya sebanyak 14 desa/kelurahan, desa swakarya sebanyak 125 desa/kelurahan, dan desa swasembada sebanyak 38 desa/kelurahan (Badan Pusat Statistika, 2014).

Kabupaten Karanganyar memiliki relief yang beraneka ragam yaitu dataran tinggi dan dataran rendah. Rata-rata ketinggian wilayah di Kabupaten Karanganyar yaitu sebesar 511 meter di atas permukaan air laut. Wilayah terendah di Kabupaten Karanganyar berada di Kecamatan Kebakkramat dengan ketinggian sebesar 80 mdpl sedangkan wilayah tertinggi di Kabupaten Karanganyar berada di Kecamatan Tawangmangu dengan ketinggian mencapai 2.000 mdpl.

Penggunaan lahan di Kabupaten Karanganyar terbesar digunakan untuk tanah kering. Tanah kering di Kabupaten Karanganyar seluas 55.038,19 Ha dan tanah sawah di Kabupaten Karanganyar seluas 22.340,45 Ha. Tanah kering di Kabupaten 
Karanganyar terbagi menjadi pekarangan/ bangunan, tegalan/kebun, padang gembala, tambak/kolam, hutan negara, perkebunan, dan lain-lain.

Produk Domestik Regional Bruto (PDRB) didefinisikan sebagai jumlah nilai tambah yang dihasilkan oleh seluruh unit usaha dalam suatu wilayah atau merupakan jumlah seluruh nilai akhir barang dan jasa yang dihasilkan oleh seluruh unit ekonomi di suatu wilayah. Keadaan perekonomian di Kabupaten Karanganyar, dapat dilihat dari nilai PDRB atas dasar harga konstan tahun 2000 pada Tabel 1.

\section{Total Share}

Analisis shift share merupakan teknik yang sangat berguna dalam menganalisis perubahan struktur ekonomi daerah dalam penelitian ini yaitu Kabupaten Karanganyar dibandingkan dengan daerah regional atau nasional, dalam penelitian ini adalah Provinsi Jawa Tengah.
Tujuan analisis ini adalah untuk menentukan kinerja atau produktivitas kerja perekonomian subsektor pertanian Kabupaten Karanganyar dengan cara membandingkannya dengan Provinsi Jawa Tengah. Dalam penelitian ini digunakan variabel pendapatan yaitu PDRB atas dasar harga konstan untuk menguraikan pertumbuhan ekonomi subsektor pertanian terhadap pembangunan daerah Kabupaten Karanganyar. Analisis shift share subsektor pertanian Kabupaten Karanganyar tahun 20092013 dapat dilihat pada Tabel 2. Jumah keseluruhan (Total Share) subsektor tanaman bahan makanan menunjukkan jumlah yang positif sebesar 173.644,66 juta rupiah yang mempunyai arti bahwa pertumbuhan subsektor tanaman bahan makanan di Kabupaten Karanganyar relatif lebih cepat dibanding subsektor tanaman bahan makanan Provinsi Jawa Tengah.

Tabel 1. PDRB Atas Dasar Harga Konstan Tahun 2000 Kabupaten Karanganyar Tahun 2009-2013

\begin{tabular}{|c|c|c|c|c|c|}
\hline \multirow{2}{*}{ Lapangan Usaha } & \multicolumn{5}{|c|}{ PDRB Atas Dasar Harga Konstan Tahun 2000 (juta rupiah) } \\
\hline & 2009 & 2010 & 2011 & 2012 & 2013 \\
\hline Industri Pengolahan & $2.646 .368,64$ & $2.769 .046,93$ & $2.946,326,79$ & $3.128 .949,26$ & $3.316 .438,83$ \\
\hline Pertanian & $996.230,41$ & 1.147.090,09 & $1.158 .318,76$ & $1.217 .443,88$ & $1.253 .460,36$ \\
\hline Perdagangan & $518.411,95$ & $560.665,60$ & $605.593,15$ & $637.303,32$ & $677.458,49$ \\
\hline Jasa-jasa & $429.059,93$ & $463.026,68$ & $499.812,85$ & $525.625,79$ & $551.670,55$ \\
\hline Angkutan dan Komunikasi & $141.756,51$ & $151.172,77$ & $160.352,40$ & $172.439,04$ & $181.919,28$ \\
\hline Bangunan & $124.149,85$ & $129.900,06$ & $136.568,44$ & $143.589,49$ & $153.703,19$ \\
\hline $\begin{array}{l}\text { Lembaga Keuangan, Sewa } \\
\text { Bangunan, dan Jasa Perusahaan }\end{array}$ & $108.271,02$ & $114.698,80$ & $122.436,74$ & $132.179,05$ & $141.564,92$ \\
\hline Listrik, Gas, dan Air minum & $70.052,49$ & $73.016,74$ & $77.206,01$ & $82.077,74$ & $88.456,76$ \\
\hline Pertambangan dan Penggalian & $42.249,08$ & $43.817,82$ & $45.449,85$ & $47.269,54$ & $49.832,72$ \\
\hline TOTAL & $5.076 .549,88$ & $5.452 .435,49$ & $5.374 .688,88$ & $6.086 .877,11$ & $6.414 .505,10$ \\
\hline
\end{tabular}

Sumber: BPS Kabupaten Karanganyar, 2014

Tabel 2. Analisis Shift Share Subsektor Pertanian Kabupaten Karanganyar Tahun 2009-2013

\begin{tabular}{lrrrr}
\hline \multicolumn{1}{c}{ Subsektor Pertanian } & $\begin{array}{c}\text { National Growth } \\
\text { (juta rupiah) }\end{array}$ & $\begin{array}{c}\text { Industry Mix } \\
\text { (juta rupiah) }\end{array}$ & $\begin{array}{c}\text { Competitive } \\
\text { Share } \\
\text { (juta rupiah) }\end{array}$ & $\begin{array}{c}\text { Total Share } \\
\text { (juta rupiah) }\end{array}$ \\
\hline Subsektor Tanaman Bahan & $65.921,04$ & $-14.541,98$ & $122.265,60$ & $173.644,66$ \\
Makanan & $8.559,10$ & $-459,71$ & $16.828,85$ & $24.928,24$ \\
Subsektor Perkebunan & $24.193,46$ & $29.689,77$ & $2.790,98$ & $56.674,21$ \\
Subsektor Peternakan & 501,83 & 88,19 & 239,46 & 829,48 \\
Subsektor Kehutanan & 526,32 & $-16,81$ & 643,86 & $1.153,37$ \\
\hline Subsektor Perikanan & & & &
\end{tabular}

Sumber: Analisis Data Sekunder, 2016 
Subsektor tanaman bahan makanan di Kabupaten Karanganyar dapat memberikan kontribusi yang sangat besar terhadap PDRB sektor pertanian Kabupaten Karanganyar sehingga pertumbuhan ekonomi sektor pertanian di Kabupaten Karanganyar dapat mengalami pergeseran dari perekonomian tradisional ke pereknomonian modern. Namun pengaruh komponen bauran industri (Industry Mix) mempunyai efek negatif, hal ini menyebabkan penurunan PDRB Kabupaten Karanganyar sebesar $-14.541,98$ juta rupiah. Pertumbuhan subsektor tanaman bahan makanan dalam sisi PDRB tumbuh relatif lambat dibandingkan subsektor tanaman bahan makanan di Provinsi Jawa Tengah. Hal ini dapat terjadi karena masih adanya komoditi yang belum diusahakan secara intensif. Kabupaten Karanganyar cenderung memfokuskan produksi pangan pada komoditi padi sehingga komoditi tanaman bahan makanan yang lainnya kurang dikembangkan.

$$
\text { Jumlah keseluruhan kinerja }
$$

perekonomian (Total Share) subsektor perkebunan menunjukkan jumlah yang positif yaitu sebesar 24.928,24 juta rupiah yang mempunyai arti bahwa pertumbuhan subsektor perkebunan Kabupaten Karanganyar relatif lebih cepat dibanding pertumbuhan subsektor perkebunan di Provinsi Jawa Tengah. Namun pengaruh komponen bauran industri (Industry Mix) subsektor perkebunan mempunyai efek negatif, pertumbuhan PDRB subsektor perkebunan di Kabupaten Karanganyar sebesar $-459,71$ juta rupiah. Pertumbuhan subsektor perkebunan dalam sisi PDRB Kabupaten Karanganyar tumbuh relatif lambat jika dibandingkan pertumbuhan subsektor perkebunan di Provinsi Jawa Tengah. Lahan perkebunan yang dominan di Kabupaten Karanganyar merupakan lahan perkebunan rakyat, namun modal yang dimiliki oleh masyarakat untuk mengelola perkebunan masih minim. Modal yang minim tersebut menyebabkan pengelolaan tanaman perkebunan masih belum intensif, bahkan ada beberapa komoditi yang belum menghasilkan pada tahun 2013, antara lain vanili, kopi arabica, dan kelapa dalam.

Jumlah keseluruhan (total share) subsektor peternakan menunjukkan jumlah yang positif yaitu sebesar 56.674,21 juta rupiah yang mempunyai arti bahwa pertumbuhan subsektor peternakan di Kabupaten Karanganyar relatif lebih cepat jika dibandingkan dengan pertumbuhan subsektor peternakan di tingkat Provinsi Jawa Tengah. Pertumbuhan subsektor peternakan cukup memberikan kontribusi PDRB untuk perekonomian di Kabupaten Karanganyar sebagai pendorong eknomi modern.

Jumlah keseluruhan (total share) subsektor kehutanan menunjukkan jumlah yang positif yaitu sebesar 829,48 juta rupiah yang mempunyai arti bahwa pertumbuhan subsektor kehutanan di Kabupaten Karanganyar relatif lebih cepat jika dibandingkan dengan pertumbuhan subsektor kehutanan di tingkat Provinsi Jawa Tengah. Pertumbuhan subsektor kehutanan memberikan kontribusi PDRB untuk perekonomian di Kabupaten Karanganyar sebagai pendorong ekonomi modern.

Jumlah keseluruhan (total share) subsektor perikanan menunjukkan jumlah yang positif yaitu sebesar 1.153,37 juta rupiah yang mempunyai arti bahwa pertumbuhan subsektor perikanan di Kabupaten Karanganyar relatif lebih cepat jika dibandingkan dengan pertumbuhan subsektor perikanan di tingkat Provinsi Jawa Tengah. Pertumbuhan subsektor perikanan cukup memberikan kontribusi PDRB untuk perekonomian di Kabupaten Karanganyar sebagai pendorong ekonomi modern. Pengaruh bauran industri (Industry Mix) memiliki efek negatif, hal ini menyebabkan pertumbuhan PDRB di Kabupaten Karanganyar relatif lebih lambat, dengan nilai sebesar $-16,81$ juta rupiah. Hal ini terjadi karena kawasan peruntukan perikanan di Kabupaten Karanganyar hanya tangkap sungai dan bendungan/danau/embung.

\section{Kontribusi dan Laju Pertumbuhan}

\section{Kontribusi}

Kontribusi yang diberikan oleh subsektor pertanian dapat menyumbang PDRB bagi sektor perekonomian di Kabupaten Karanganyar sehingga dapat membantu dalam pembangunan daerah di Kabupaten Karanganyar. Kontribusi subsektor pertanian dapat diketahui melalui perbandingan PDRB subsektor pertanian terhadap total PDRB sektor pertanian. Kontribusi subsektor pertanian penting untuk diketahui dalam perencanaan pembangunan suatu daerah. 
Fransisca Erna S., M. Harisudin, Wiwit R. : Analisis Peran Subsektor Pertanian ...

Tabel 3. Kontribusi Subsektor Pertanian Terhadap Sektor Pertanian Kabupaten Karanganyar Tahun 20092013

\begin{tabular}{|c|c|c|c|c|c|c|}
\hline Subsektor Pertanian & $\begin{array}{c}2009 \\
(\%)\end{array}$ & $\begin{array}{c}2010 \\
(\%)\end{array}$ & $\begin{array}{c}2011 \\
(\%)\end{array}$ & $\begin{array}{c}2012 \\
(\%)\end{array}$ & $\begin{array}{c}2013 \\
(\%)\end{array}$ & $\begin{array}{l}\text { Rata-Rata } \\
(\%)\end{array}$ \\
\hline $\begin{array}{l}\text { Subsektor Tanaman Bahan } \\
\text { Makanan }\end{array}$ & 66,12 & 68,26 & 66,71 & 67,19 & 66,40 & 66,94 \\
\hline Subsektor Perkebunan & 8,58 & 8,55 & 8,89 & 8,70 & 8,81 & 8,71 \\
\hline Subsektor Peternakan & 24,27 & 22,23 & 23,38 & 23,11 & 23,81 & 23,36 \\
\hline Subsektor Kehutanan & 0,50 & 0,46 & 0,48 & 0,48 & 0,47 & 0,48 \\
\hline Subsektor Perikanan & 0,53 & 0,50 & 0,54 & 0,51 & 0,51 & 0,52 \\
\hline Total & 100,00 & 100,00 & 100,00 & 100,00 & 100,00 & 100,00 \\
\hline
\end{tabular}

Sumber: Analisis Data Sekunder, 2016

Subsektor tanaman bahan makanan memberikan rata-rata kontribusi terbesar bagi sektor pertanian dalam perekonomian Kabupaten Karanganyar yaitu sebesar $66,94 \%$. Subsektor tanaman bahan makanan memberikan kontribusi yang cenderung fluktuatif dari tahun 2009 hingga 2013 yaitu masing-masing sebesar 66,12\%; 68,26\%; $66,71 \%$; 67,19\%; dan 66,40\%. Subsektor perkebunan memberikan rata-rata kontribusi bagi sektor pertanian dalam perekonomian Kabupaten Karanganyar sebesar 8,71\%. Kontribusi subsektor perkebunan dari tahun 2009 hingga 2013 hampir dapat dikatakan stabil yaitu masing-masing sebesar $8,58 \%$; $8,55 \% ; 8,89 \% ; 8,70 \%$; dan $8,81 \%$. Hal ini karena hampir semua tanaman perkebunan yang dibudidayakan di Kabupaten Karanganyar dapat dipanen setiap tahunnya, seperti komoditi cengkeh, kelapa, dan tebu

Subsektor peternakan memberikan kontribusi terbesar kedua setelah subsektor tanaman bahan makanan. Subsektor peternakan memberikan rata-rata kontribusi bagi sektor pertanian dalam perekonomian Kabupaten Karanganyar sebesar 23,36\%. Subsektor peternakan memberikan kontribusi yang cenderung fluktuatif dari tahun 2009 hingga 2013 yaitu masing-masing sebesar 24,27\%; $22,23 \% ; 23,38 \% ; 23,11 \%$ : dan $23,81 \%$. Hasil produksi ternak di Kabupaten Karanganyar didominasi oleh telur ayam ras dan daging. Ketersediaan protein hewani Kabupaten Karanganyar pada tahun 2009 hingga 2012 jumlahnya melebihi padi-padian, umbi-umbian, kacang-kacangan bahkan sayur dan buah. Banyaknya hasil produksi ternak di Kabupaten Karanganyar menyesuaikan dengan pola konsumsi masyarakat Kabupaten Karanganyar yang cenderung mengkonsumsi pangan hewani dibandingkan sayur dan buah.

Subsektor kehutanan memberikan ratarata kontribusi terkecil bagi sektor pertanian dalam perekonomian Kabupaten Karanganyar sebesar 0,48\%. Subsektor perkebunan memberikan kontribusi yang cenderung fluktuatuif dari tahun 2009 hingga 2013 yaitu masing-masing sebesar $0,50 \% ; 0,46 \% ; 0,48 \%$; $0,48 \%$; dan $0,47 \%$. Hal ini karena lahan penggunaan untuk hutan mengalami penurunan yang drastis pada tahun 2011 yaitu sebesar 5007 Ha. Selain itu fungsi hutan yang diperuntukkan sebagai hutan produksi hanya $259 \mathrm{Ha}$ dari 3.201,83 Ha hutan yang ada di Kabupaten Karanganyar. Subsektor perikanan memberikan rata-rata kontribusi bagi sektor pertanian dalam perekonomian Kabupaten Karanganyar sebesar $0,52 \%$. Subsektor perkebunan memberikan kontribusi yang cenderung fluktuatuif dari tahun 2009 hingga 2013 yaitu masing-masing sebesar $0,53 \%$; $0,50 \% ; 0,54 \% ; 0,51 \%$; dan $0,51 \%$.

\section{Laju Pertumbuhan}

Laju pertumbuhan subsektor pertanian dapat menunjukkan tingkat perkembangan, baik itu peningkatan maupun penurunan dari masingmasing subsektor pertanian di Kabupaten Karanganyar. Laju pertumbuhan subsektor pertanian ditunjukkan dengan angka bertanda positif dan negatif. Subsektor yang memiliki laju pertumbuhan positif memiliki arti bahwa subsektor tersebut mengalami peningkatan sedangkan subsektor yang memiliki laju pertumbuhan negatif mempunyai arti bahwa subsektor tersebut mengalami penurunan. 
Fransisca Erna S., M. Harisudin, Wiwit R. : Analisis Peran Subsektor Pertanian ...

Tabel 4. Laju Pertumbuhan Subsektor Pertanian Kabupaten Karanganayar

\begin{tabular}{lrrrrr}
\hline \multirow{2}{*}{ Subsektor Pertanian } & \begin{tabular}{c} 
Tahun \\
2009-2010 \\
\cline { 2 - 5 }
\end{tabular} & $\begin{array}{c}2010-2011 \\
(\%)\end{array}$ & $\begin{array}{c}2011-2012 \\
(\%)\end{array}$ & $\begin{array}{c}2012-2013 \\
(\%)\end{array}$ & $\begin{array}{c}\text { Rata-Rata } \\
(\%)\end{array}$ \\
\hline Subsektor Tanaman & 18,88 & $-1,32$ & 5,87 & 1,75 & 6,29 \\
Bahan Makanan & 14,61 & 5,10 & 2,87 & 4,22 & 6,70 \\
Subsektor Perkebunan & 5,48 & 6,20 & 3,92 & 6,05 & 5,41 \\
Subsektor Peternakan & 6,06 & 4,90 & 4,02 & 0,70 & 3,92 \\
Subsektor Kehutanan & 9,14 & 8,72 & $-0,44$ & 3,21 & 5,16 \\
Subsektor Perikanan & 15,14 & 0,98 & 5,10 & 2,96 & 6,05 \\
\hline Sektor Pertanian & & & & & \\
\hline
\end{tabular}

Sumber: Analisis Data Sekunder, 2016

Rata-rata laju pertumbuhan subsektor tanaman bahan makanan sebesar 4,88\%. Laju pertumbuhan subsektor mengalami laju pertumbuhan negatif pada tahun 2009 dan 2011 yang artinya subsektor perkebunan mengalami penurunan laju pertumbuhan. Pada tahun 2009 dan 2011, subsektor tanaman bahan makanan mengalami penurunan laju pertumbuhan karena produksi komoditi tanaman bahan makanan yang mengalami penurunan adalah ubi jalar, kacang tanah, padi sawah, dan padi gogo dengan masing-masing persentase produksi turun sebesar $1,53 \% ; 0,13 \% ; 5,09 \%$; dan $0,82 \%$ serta menurunnya produksi tanaman bahan makanan disebabkan karena cuaca yang buruk pada tahun 2011, selain itu terjadi serangan hama wereng yang menyebabkan produksi padi menurun.

Rata-rata laju pertumbuhan subsektor perkebunan sebesar 5,75\%. Subsektor perkebunan dari tahun 2009 hingga 2013 mengalami laju pertumbuhan positif. Produksi tanaman perkebunan di Kabupaten Karanganyar didominasi oleh produksi kelapa, tebu, kunir, dan jahe. Pabrik Jamu Air Mancur dan pabrik jamu skala rumah tangga yang tersebar di Kabupaten Karanganyar, mendorong masyarakat untuk menyediakan bahan baku dengan untuk mengembangkan komoditi jahe, kencur, dan kunir di tegalan yang mereka miliki yang kemudian dapat digunakan untuk persediaan bahan baku bagi pabrik jamu.

Rata-rata laju pertumbuhan subsektor peternakan sebesar $5,27 \%$. Laju pertumbuhan subsektor peternakan bernilai positif dari tahun 2009 hingga tahun 2013, hal ini berarti laju pertumbuhan subsektor peternakan mengalami peningkatan. Pertumbuhan hasil produksi ternak tertinggi tahun 2009 adalah telur itik yaitu sebesar 36,01\%. Pada tahun 2010 semua pertumbuhan hasil produksi ternak meningkat. Pertumbuhan produksi daging pada tahun 2011 mengalami peningkatan hingga $11,04 \%$. Selain produksi daging yang mengalami peningkatan, telur ayam buras dan telur puyuh juga mengalami peningkatan masing-masing sebesar $0,12 \%$ dan 5,89\%. Tahun 2012 laju pertumbuhan subsektor peternakan lebih kecil dari tahun sebelumnya yaitu sebesar 3,92\%. Hal ini terjadi karena produksi telur itik mengalami penurunan hampir $10 \%$. Tahun 2013 laju pertumbuhan subsektor peternakan kembali meningkat menjadi $6,05 \%$. Hal ini terjadi karena hampir semua hasil produksi ternak di Kabupaten Karangayar mengalami peningkatan, hanya produksi telur itik yang mengalami penurunan.

Besarnya laju pertumbuhan subsektor kehutanan dari tahun 2009 hingga 2013 berturut-turut sebesar 4,35\%; 6,06\%; 4,90\%; $4,02 \%$; dan $0,70 \%$. Subsektor kehutanan merupakan subsektor dengan laju pertumbuhan terendah di Kabupaten Karanganyar yaitu sebesar 4,01\%. Hal ini terjadi karena luas lahan hutan di Kabupaten Karanganyar dari tahun 2010 hingga 2013 mengalami penurunan terusmenerus. Luas lahan hutan di Kabupaten Karanganyar dari tahun 2010 hingga 2013 berturut-turut sebesar 9,729 ha; 4,722 ha; 4,431 ha; dan 1.836,34 ha. Berkurangnya lahan hutan di Kabupaten Karanganyar terjadi karena adanya perubahan fungsi penggunaan lahan. Lahan hutan berubah fungsi menjadi pekarangan/bangunan karena meningkatnya kebutuhan akan tempat tinggal dengan seiring 
Tabel 5. Penentuan Klasifikasi Subsektor Pertanian di Kabupaten Karanganyar Tahun 2009-2013

\begin{tabular}{|c|c|c|}
\hline $\begin{array}{l}\text { Rerata Laju } \\
\text { Pertumbuhan } \\
\text { Subsektor }\end{array}$ & $\begin{array}{l}\text { Kontribusi Besar } \\
\quad(y i>Y i)\end{array}$ & $\begin{array}{l}\text { Kontribusi Kecil } \\
(\text { yi }<\mathrm{Yi})\end{array}$ \\
\hline $\begin{array}{l}\text { Laju Pertumbuhan Cepat } \\
\qquad(\text { ri }>\text { Ri) }\end{array}$ & $\begin{array}{l}\text { Subsektor Maju dan } \\
\text { Berkembang: } \\
\text { 1. Subsektor peternakan }\end{array}$ & $\begin{array}{l}\text { Subsektor Berkembang tapi Tertekan: } \\
\text { 1. Subsektor tanaman bahan makan } \\
\text { 2. Subsektor perkebunan } \\
\text { 3. Subsektor kehutanan } \\
\text { 4. Subsektor perikanan }\end{array}$ \\
\hline $\begin{array}{l}\text { Laju Pertumbuhan Lambat } \\
\text { (ri < Ri) }\end{array}$ & Subsektor Potensial & Subsektor Tertinggal \\
\hline
\end{tabular}

Sumber: Analisis Data Sekunder, 2016

bertambahnya penduduk di Kabupaten Karanganyar.

Subsektor perikanan merupakan subsektor dengan rata-rata laju pertumbuhan tertinggi di Kabupaten Karanganyar yaitu sebesar $5,89 \%$. Laju pertumbuhan subsektor perikanan bernilai positif dari tahun 2009 hingga tahun 2013, hal ini berarti laju pertumbuhan subsektor perikanan mengalami peningkatan. Peningkatan produksi perikanan yang didukung dengan adanya keramba jaring apung. Keramba jaring apung selain sebagai tempat budidaya ikan, juga sebagai tempat pembibitan ikan. Keramba jaring apung di Kabupaten Karanganyar terdapat di 3 kecamatan yaitu Kecamatan Karanganyar, Kecamatan Colomadu, dan Kecamatan Gondangrejo. Produksi perikanan di Kabupaten Karanganyar selain berasal dari Keramba Jaring Apung juga berasal dari cek DAM, kolam air tenang, sungai, dan waduk.

\section{Klasifikasi Subsektor Pertanian}

Subsektor peternakan Kabupaten Karanganyar merupakan subsektor maju dan berkembang. Subsektor peternakan dapat dikelompokkan menjadi subsektor maju dan berkembang karena memiliki kontribusi besar dan laju pertumbuhan yang cepat. Potensi yang dimiliki oleh subsektor peternakan sehingga menjadi satu-satunya subsektor maju dan berkembang di Kabupaten Karanganyar adalah adanya perusahaan pertanian berbadan hukum bahkan perusahaan pertanian berbadan hukum tertinggi antara tahun 2003 hingga 2013 secara absolut terjadi di subsektor peternakan.

Subsektor tanaman bahan makanan, subsektor perkebunan, subsektor kehutanan, dan subsektor perikanan diklasifikasikan dalam subsektor berkembang tapi tertekan. Subsektor tanaman bahan makanan, subsektor perkebunan, subsektor kehutanan, dan subsektor perikanan di Kabupaten Karanganyar memiliki laju pertumbuhan yang lebih cepat jika dibandingkan dengan laju pertumbuhan Provinsi Jawa Tengah, namun memiliki kontribusi yang kecil jika dibandingkan dengan kontribusi di Provinsi Jawa Tengah. Kontribusi subsektor tanaman bahan makanan dapat bertambah dengan potensi-potensi yang mendukung. Adapun potensi yang dimiliki subsektor tanaman bahan makanan adalah tersedianya lahan untuk pengembangan subsektor tanaman bahan makanan dan beragamnya komoditi tanaman bahan makanan yang ada di Kabupaten Karanganyar. Subsektor perkebunan dapat didukung oleh adanya Pabrik Jamu Air Mancur dan pabrik jamu skala rumah tangga yang tersebar di Kabupaten Karanganyar, yang dapat mendorong masyarakat untuk mengembangkan komoditi jahe, kencur, dan kunyit di tegalan yang mereka miliki yang kemudian dapat digunakan untuk persediaan bahan baku bagi pabrik jamu. Potensi yang mendukung subsektor perkebunan yaitu adanya penghijauan lahan kritis di lereng Gunung Lawu. Potensi yang mendukung subsektor perikanan di Kabupaten Karanganyar 
adalah adanya keramba jaring apung yang dapat mendukung budidaya ikan di Kabupaten Karanganyar, serta banyaknya penebaran benih ikan di Kabupaten Karanganyar.

\section{Subsektor Pertanian Unggulan}

Subsektor pertanian unggulan pertama berdasarkan analisis CPI dengan kriteria kontribusi dan laju pertumbuhan adalah subsektor tanaman bahan makanan. Subsektor tanaman bahan makanan dapat menjadi subsektor unggulan pertama karena memiliki kontribusi tertinggi di Kabupaten Karanganyar. Tingginya kontribusi dan laju pertumbuhan subsektor bahan makanan didukung oleh banyaknya tanaman yang dibudidayakan, luas lahan budidaya, banyaknya rumah tangga usaha tani, dan tingginya produksi komoditi tanaman bahan makanan.

Subsektor peternakan Kabupaten Karanganyar berdasarkan hasil analisis comparative performance index menempati peringkat kedua sebagai subsektor pertanian unggulan Kabupaten Karanganyar. Nilai kriteria subsektor peternakan berdasarkan comparative performance index bernilai positif. Meskipun hasil analisis untuk subsektor peternakan bernilai positif dan menempati peringkat kedua, produksi subsektor peternakan perlu ditingkatkan sehingga pertumbuhan dan kontribusi subsektor peternakan Kabupaten Karanganyar dapat meningkat.

Subsektor perkebunan Kabupaten Karanganyar berdasarkan hasil analisis comparative performance index menempati peringkat ketiga sebagai subsektor pertanian unggulan Kabupaten Karanganyar. Pemerintah Kabupaten Karanganyar dapat menjalin kerjasama dengan perusahaan perkebunan yang beroperasi di Kabupaten Karanganyar untuk menggiatkan budidaya tanaman perkebunan.

Subsektor perikanan Kabupaten Karanganyar berdasarkan hasil analisis comparative performance index menempati peringkat keempat sebagai subsektor pertanian unggulan Kabupaten Karanganyar. Meskipun Kabupaten Karanganyar bukan merupakan daerah pesisir, Kabupaten Karanganyar memiliki fasilitas pendukung yang memadai seperti kolam air tenang yang terdapat di semua kecamatan di Kabupaten Karanganyar, cek DAM yang terdapat di 13 Kecamatan di Kabupaten Karanganyar, sungai yang mengalir di semua kecamatan di Kabupaten Karanganyar, waduk yang terdapat di Kecamatan Karanganyar, dan keramba jaring apung yang terdapat di Kecamatan Karanganyar. Beberapa komoditi yang berpotensi untuk dikembangkan dan dibudidayakan di Kabupaten Karanganyar antara lain karper, tawes, nila merah, gurami, dan lele. Subsektor kehutanan Kabupaten Karanganyar berdasarkan hasil analisis comparative performance index menempati peringkat terakhir sebagai subsektor pertanian unggulan Kabupaten Karanganyar. Produksi komoditi kehutanan di Kabupaten Karanganyar sangat perlu ditingkatkan. Peningkatan produksi komoditi kehutanan dapat dilakukan melalui rehabilitasi hutan rakyat. Kabupaten Karanganyar memiliki kondisi alam berupa perbukitan yang rentan terhadap bahaya erosi dan tanah longsor, dengan kondisi daerah yang seperti ini sebenarnya potensial untuk pengembangan komoditi kehutanan seperti karet.

Tabel 6. Penentuan Subsektor Pertanian Unggulan di Kabupaten Karanganyar

\begin{tabular}{lrcrc}
\hline \multirow{2}{*}{ Alternatif } & \multicolumn{2}{c}{ Kriteria } & \multirow{2}{*}{ Nilai Alternatif } & \multirow{2}{*}{ Peringkat } \\
\cline { 2 - 3 } & Kontribusi & Laju Pertumbuhan & & \\
\hline Subsektor Tanaman Bahan Makanan & $20.934,16$ & 160,52 & $9.668,03$ & 1 \\
Subsektor Perkebunan & $3.005,29$ & 170,93 & $1.468,13$ & 3 \\
Subsektor Peternakan & $6.832,50$ & 138,00 & $3.201,88$ & 2 \\
Subsektor Kehutanan & 100,00 & 100,00 & 100,00 & 5 \\
Subsektor Perikanan & 139,05 & 131,57 & 134,99 & 4 \\
Bobot Kriteria & 0,46 & 0,54 & & \\
\hline
\end{tabular}

Sumber: Analisis Data Sekunder, 2016 


\section{KESIMPULAN DAN SARAN}

\section{Kesimpulan}

Kesimpulan dari penelitian ini adalah (1) total share atau kinerja perekonomian subsektor tanaman bahan makanan Kabupaten Karanganyar sebesar 173.644,66 juta rupiah; total share subsektor perkebunan sebesar 24.928,24 juta rupiah; total share subsektor peternakan sebesar 56.674,21 juta rupiah; total share subsektor kehutanan sebesar 829,48 juta rupiah; dan total share subsektor perikanan sebesar 1.153,37 juta rupiah; (2) kontribusi subsektor tanaman bahan makanan, perkebunan, peternakan, kehutanan, dan perikanan berturut-turut sebesar 66,94\%; $8,71 \%$; $23,36 \%$; $0,48 \%$; dan $0,52 \%$; (3) laju pertumbuhan subsektor tanaman bahan makanan, perkebunan, peternakan, kehutanan, dan perikanan berturut-turut sebesar $4,88 \%$; $5,75 \% ; \quad 5,27 \% ; \quad 4,01 \%$; dan $5,89 \%$; (4) subsektor peternakan Kabupaten Karanganyar merupakan subsektor maju dan berkembang karena memiliki kontribusi besar dan laju pertumbuhan yang cepat. Subsektor tanaman bahan makanan, subsektor perkebunan, subsektor kehutanan, dan subsektor perikanan diklasifikasikan dalam subsektor berkembang tapi tertekan memiliki laju pertumbuhan yang lebih cepat jika dibandingkan dengan laju pertumbuhan Provinsi Jawa Tengah, namun memiliki kontribusi yang kecil jika dibandingkan dengan kontribusi di Provinsi Jawa Tengah; (5) Subsektor pertanian unggulan pertama berdasarkan hasil analisis CPI dengan kriteria total share, rerata kontribusi, dan rerata laju pertumbuhan adalah subsektor tanaman bahan makanan.

\section{Saran}

Saran yang dapat diberikan dari hasil penelitian ini adalah : (1) Pemerintah Kabupaten Karanganyar dapat meningkatkan dan mengembangkan subsektor tanaman bahan makanan dengan menerapkan diversifikasi produk tanaman bahan makanan dan penggunaan benih bermutu baik; (2) Pertumbuhan subsektor perkebunan dapat dapat ditingkatkan dengan memberikan modal bagi petani sehingga usaha tani yan dikembangkan dapat berjalan intensif, penyebaran teknologi kepada petani terutama mengenai benih bermutu baik; (3) Subsektor peternakan dapat ditingkatkan dengan mengadakan sosialisai mengenai budidaya ternak terutama ternak ayam pedaging, yang potensial untuk dikembangkan; (4) Subsektor kehutanan merupakan subsektor dengan kontribusi dan laju pertumbuhan yang terkecil di Kabupaten Karanganyar, sehingga perlu ditingkatkan dengan cara rehabilitasi hutan rakyat; (5) Kabupaten Karanganyar bukan merupakan daerah pesisir, namun peran subsektor perikanan dapat ditingkatkan dengan cara memanfaatkan produksi ikan pada keramba jaring apung dan kolam air secara optimal; (6) Perlu penelitian lebih lanjut mengenai prioritas pengembangan komoditas tiap subsektor pertanian untuk rencana pengembangan subsektor pertanian dalam pembangunan di Kabupaten Karanganyar.

\section{DAFTAR PUSTAKA}

Arsyad, Lincolin. 1992. Ekonomi Pembangunan Cetakan Pertama Edisi Kedua. Yogyakarta: STIE YKPN Press

Arsyad, Lincolin. 2005. Pengantar Perencanaan Pembangunan Ekonomi Daerah. Yogyakarta: BPFE-UGM.

BPS Kabupaten Karanganyar. 2014. Karanganyar dalam Angka 2013 Karanganyar: Badan Pusat Statistik Kabupaten Karanganyar.

Dinc, Mustafa. 2002. Regional and Local Economic Analysis Tools. Washington DC: World Bank Institute.

Maria. 2007. Pertumbuhan dan Perubahan Struktur Sektor Pertanian Provinsi Jawa Tengah: Sebelum dan Setelah Pelaksanaan Otonomi Daerah. Jurnal AGRIC XIX (1 dan 2): 12-25Saragih, Rudhianto. 2015. Perencanaan Wilayah dan Pengembangan Ekonomi Lokal Berbasis Pertanian: Teori dan Aplikasi. Yogyakarta: Pustaka Pelajar.

Sjafrizal, 2008. Ekonomi Regional, Teori dan Aplikasi. Jakarta: Niaga Swadaya.

Yun Shi dan Yang. 2008. A Review of ShiftShare Analysis and Its Application in Tourism. International Journal of Management Perspectives I (1): 21-30 